\title{
Assessment of Pattern of Self-administration during Pregnancy in Tehran and Sanandaj
}

Mamak Shariat ${ }^{1}$, Mozhdeh Zarei ${ }^{2}$, Nasrin Soufizadeh ${ }^{3}$, Sedigheh Hantoushzadeh ${ }^{4}, \underline{\text { Raheleh Moradi }^{5}}$

1. Full Professor in Mother and Child Health, Institute of Family Health. Maternal, Fetal and Neonatal Research Center, Tehran University of Medical Sciences, Tehran, Iran. ORCID ID: 0000-0002-7547-8004

2. MSc in Midwifery and MPH Reproductive Health, Deputy of research and technology, Kurdistan University of Medical Sciences, Sanandaj, Iran. ORCID ID: 0000-0001-6820-4286

3. Assistant Professor in Obstetrics and Gynecology, Faculty of Medicin, Kurdistan University of Medical Sciences, Sanandaj, Iran. ORCID ID: 0000-0001-8527-6564

4. Full Professor in Perinatology, Institute of Family Health, Maternal, Fetal and Neonatal Research Center, Tehran University of Medical Sciences, Tehran, Iran. ORCID ID: 0000-0003-3779-9218

5. MSc in Midwifery, Institute of Family Health, Maternal, Fetal and Neonatal Research Center, Tehran University of Medical Sciences, Tehran, Iran., (Corresponding Author), Tel: +98 21 61192357, Email: raheleh.moradi1987@ gmail.com, ORCID ID: 0000-0002-4841-5665

\begin{abstract}
Background and Aim: Pregnancy is associated with many physiological changes that can affect the effectiveness of drugs. Our purpose in this study was to asses the pattern of drug use during pregnancy, self-administration consumption, maternal and fetal complications.

Materials and Methods: This study was conducted on 1300 pregnant women referred to health centers of Sanandaj and south of Tehran during 2016-17. The information was obtained by interviewing mothers and examining the documentation of the delivery. Finally all data analysis was performed by SPSS software, v.18 and Chi square and T- test.

Results: The largest age group of participants was 18-35 years old (80.2\%). The most of them were housewives $(78.5 \%)$ and $87.3 \%$ of them had at least a diploma. self-administration consumption was significantly more common in mothers with unwanted pregnancies and those who received their prenatal care from unskilled persons $(\mathrm{P}<0.05)$.

Conclusion: In women with self-administration consumption, the mean of education was less. It is concluded that education system has a important role in the change of knowledge, attitude and performance. self-administration consumption more happened between they who were advised by unskilled assistance and they who had uwanted pregnancy. Therefore, we should extend Reproductive Health services for development of Iranian women and mothers society.
\end{abstract}

Keywords: Drug use pattern, Pregnancy, Self-administration consumption

Received: May 31, 2019 Accepted: Sep 23, 2019

How to cite the article: Mamak Shariat, Mozhdeh Zare, Nasrin Soufizadeh, Sedigheh Hantoushzadeh,

Raheleh Moradi. Assessment of pattern of self-administration during pregnancy in Tehran and Sanandaj. SJKU 2020;25(1):54-61.

Copyright ( 2018 the Author (s). Published by Kurdistan University of Medical Sciences. This is an open access article distributed under the terms of the Creative Commons Attribution-Non Commercial License 4.0 (CCBYNC), where it is permissible to download, share, remix, transform, and buildup the work provided it is properly cited. The work cannot be used commercially without permission from the journal 


\title{
بررسى الكوى مصرف خودسر انه دارو در دوران باردارى در شهر هاى تهران و سنندج
}

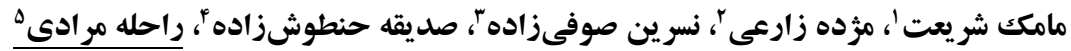

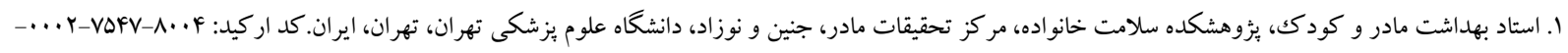

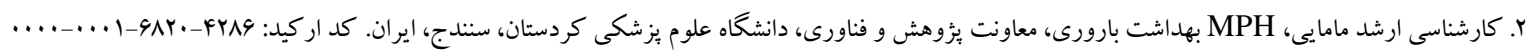

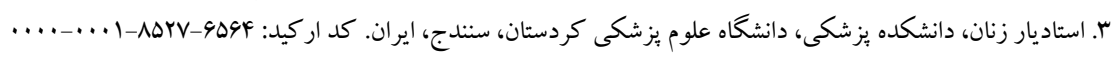

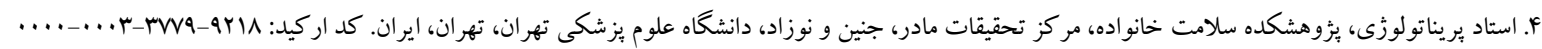

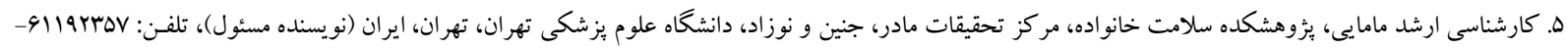

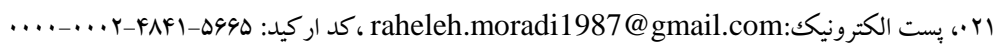

جكکبه

زمينه و هدف: باردارى با تغييرات فيزيولوزيكك بسيارى همراه است كه مى تواند اثر گذارى داروها را نيز تحـت تأثير قرار دهـــ.

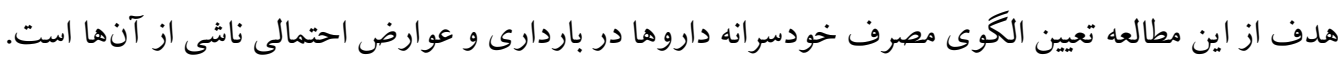

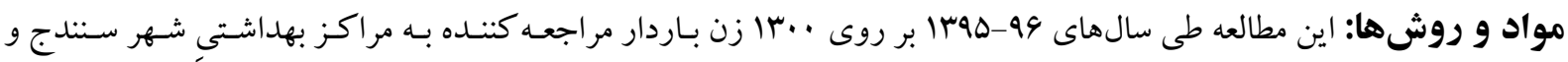

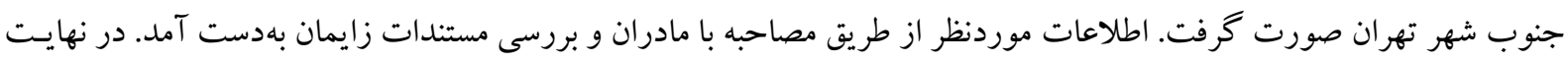

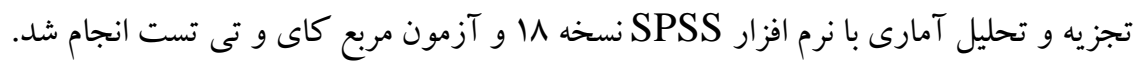

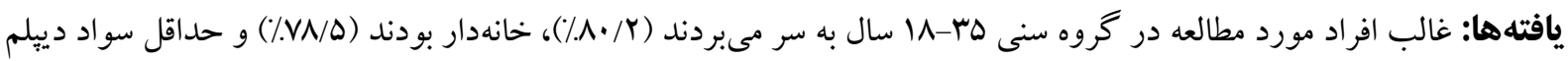

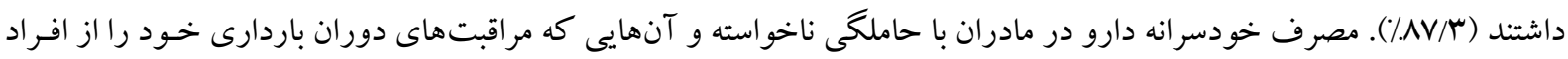

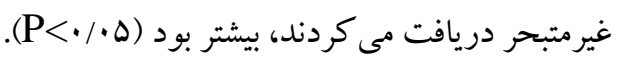

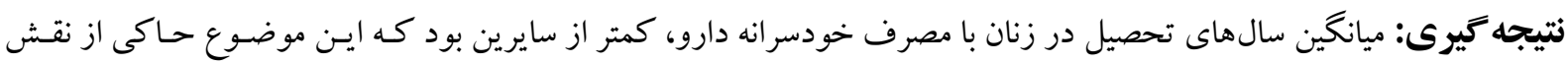

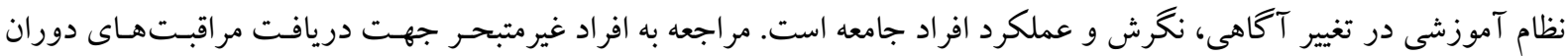

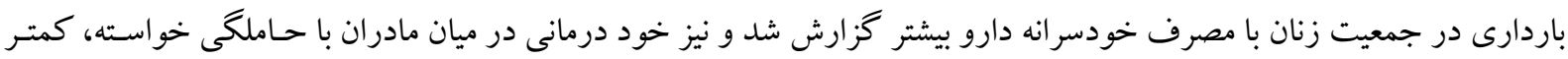

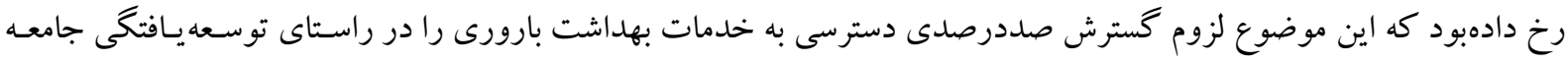
زنان و مادران ايرانى مىرساند. كلمات كليدى: الكوى مصرف دارو، باردارى، مصرف خورن خودسرانه دارو

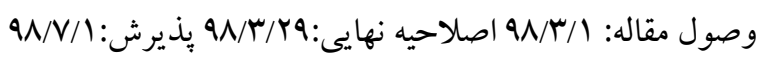


ارزيـابى شـــ كــه رابطـهـ وارونـه و معنسى دارى را بـا سـن، تحصـيلات و برخسوردارى از مراقبـتهــاى بـاردارى نشـان مىداد(ي و V). از آنجايى كه انجام مطالعـات مداخلهاى در زمينـه موضـوع مـورد يـزروهش، مســلزم اجـراى مطالعـات مقطعى جهت اطلاع از وضعيت موجود است، اين مطالعه بـاـ هدف تعيين الكوى مصرف خودسرانه دارو در زنـان بـاردار

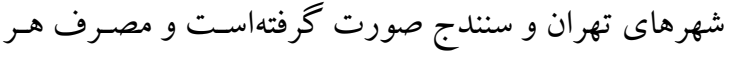
كونه دارو به شكل خودسر انه و بروز عوارض احتمالى ناشى فهر از آنها مورد بررسى قرار گرفتهاست.

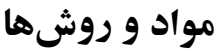

در اين مطالعه مقطعى مشتر كك بين دانشـاه علوم بز شـكى

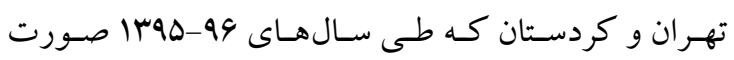

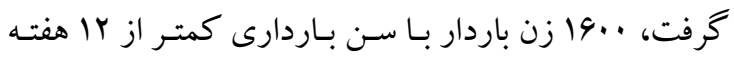

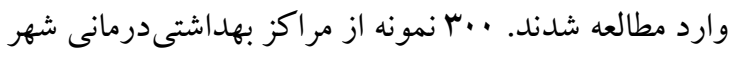

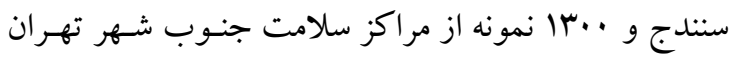

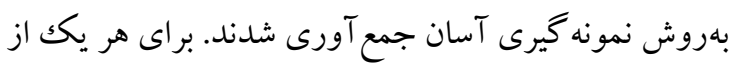
مادران ضـمن ارائه كليه خــدمات روتين دوران بـاردارى، يرسشنامهاى توسط ماماهاى شاغل در مراكز سلامت تكميـل

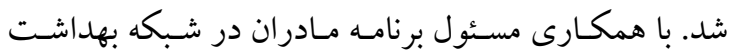

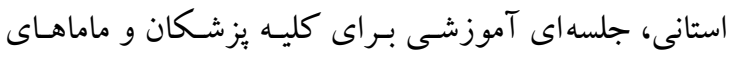

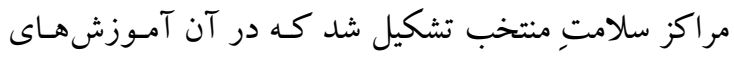

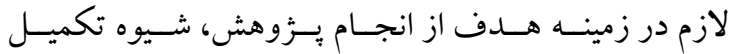
يرسشنامه و جزئيات انجام مصاحبه صحيح داده شـد. جهت استخر اج اطلاعات نزديكك به واقعيـ، همكـاران مصـاحبه-

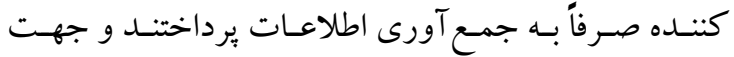
رعايت ملاحظات اخلاقى در ثزوهش، در صورتى كـه مـادر سابقه مصرف هر نوع دارو يا روش درمانى مخاطرهآميز را

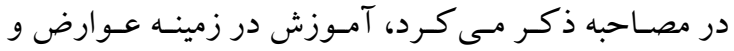
خطرات مربوط به مصـرف دارو و هشــارهاى لازم، توسط

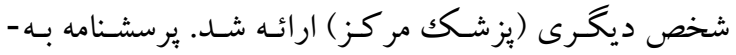
صورت محقق ساخته و شامل r سؤ ال بود كه روايى آن به

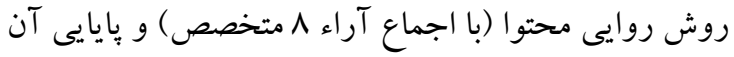

مقدمله

باردارى با تغييـرات فيز يولوزيـك بسـيارى همـر اه اسـت، از

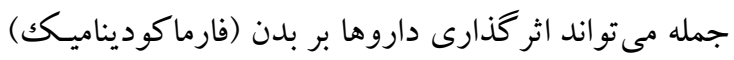
و بالعكس اثر و رفتار بدن بر روى داروها (فارماكو كينتيك)

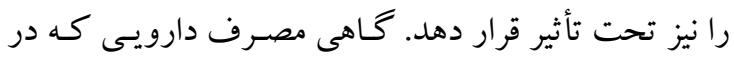

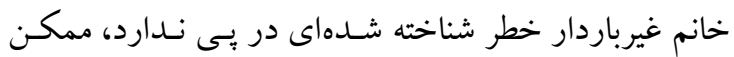
است در دوران باردارى اثرات نـامطلوبى در مـادر و جنين ايجـاد نمايــ( (1). از طرفى اجتــاب از درمـان دارويسى در باردارى ممكن نيست؛ زيرا بعضى از زنان باردار بهدليل ابتلا به بيمارىهاى مزمن نيـاز بـه مصـرف دارو خواهنـد داشـت.

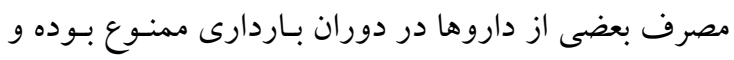
تعدادى از داروهاى بر مصرف و معمـول، در ايـن دوران بـاـ خطر سقط جنين و نو اقص مادرزادى همر هــتند. سـازمان

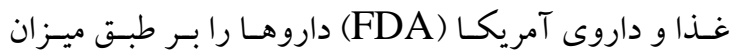
احتمال بروز عوارض ناشى از مصرف بر روى جنين در يـنـ

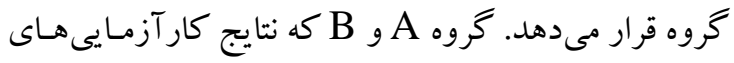
انسانى و يا مطالعات بر روى حيوانات، خطرى را براى جنين

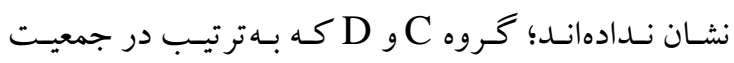

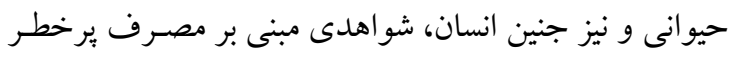

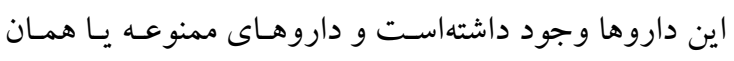

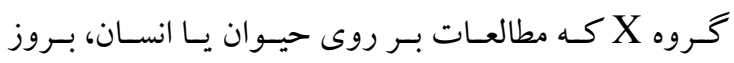

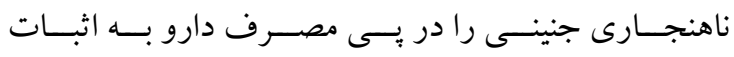

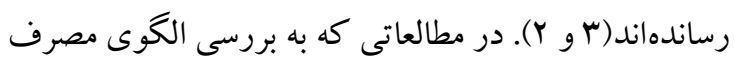

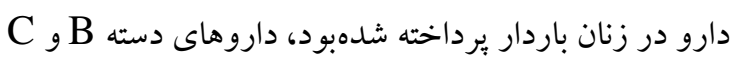

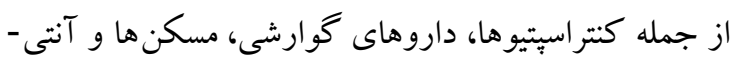
بيوتيككها بيشترين داروهاى مورد استفاده در باردارى بودند

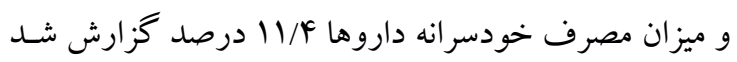
كه با افزايش سطح تحصيلات كـاهش معنى دارى را نشـان مى داد(هو F). در مطالعه ديخرى در جمعيـت زنـان بـاردار،

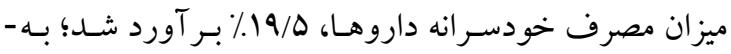

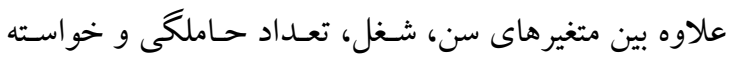

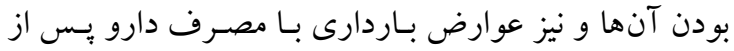
اطلاع از باردارى، ارتباط معنى دارى رؤيـت شـد (9). در دو يـرزوهش ديخـر، شـيوع سوءمصـرف مـو اد در زنـان بـاردار 
آن، مورد توجه قرار گرفت كه بازه كمينه در سنندج (I/V)

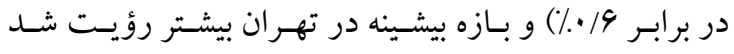

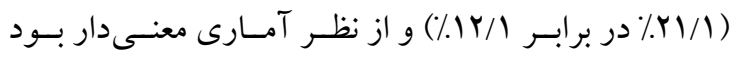
(P-value= •/·1) به طرز معنى دارى در مادران تهرانى بيشتر ديده شــ (1 (.). (P-value= سندجى مشاهده شد كه همخى داروهاى مجاز و مورد تأييد

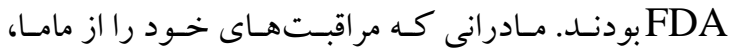
يز شكك عمومى يا متخصص دريافت كردهبودنـد، كمترين

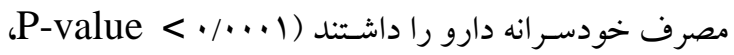

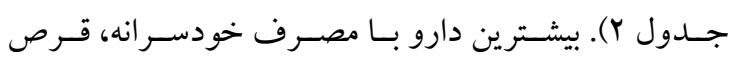
استامينوفن و علت شايع مصرف آن نيز تسكين سـردرد بـود. در مادران با باردارى اول، حداكثر يكك مورد سقط و بـدون

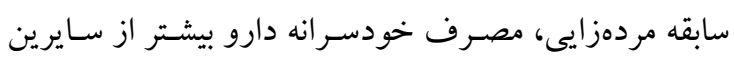

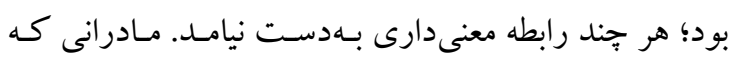

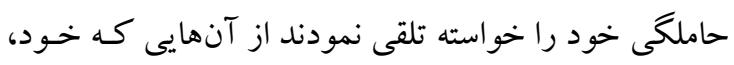

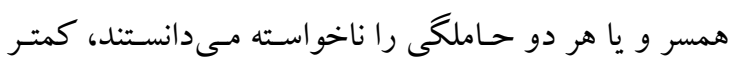

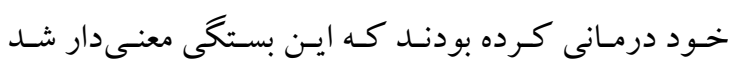

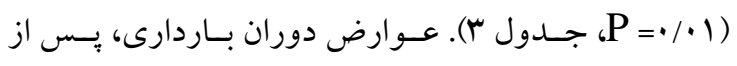
زايمان و نيز دوره نوزادى بر حسب مصرف خودسـرانه دارو

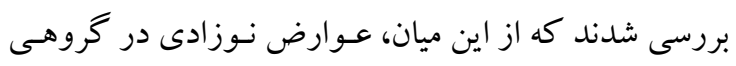

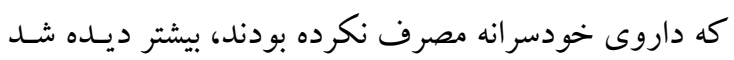

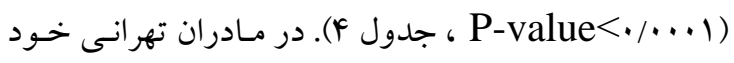
اظهارى مبنى بر مصرف خودسر انه داروها گزارش نشد.
به روش آزمون مجدد مورد بررسى قرار گرفت. در مجموع اطلاعات مربوط به مصرف داروها و عوارض آنها از طريق مصاحبه با مادر و دادههاى مربوط به عوارض حين زايمان از

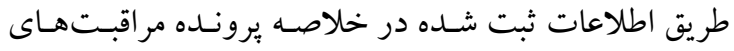
بيمارستانى بهدست آمد؛ علاوه بر ايـن اطلاعـات مربـوط بـه

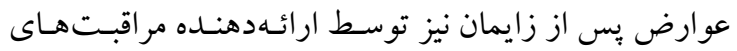

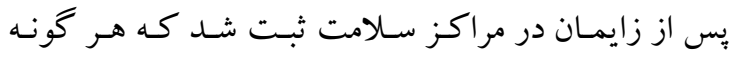
عارضه بريناتال از جمله ديابـت بـاردارى، فشـار خـون بـالا، خونريزى، اختلالات تيروئيدى، تهوع و استفراغ در مـادر و

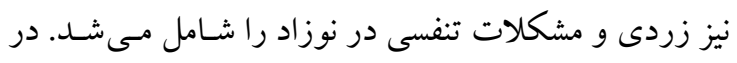

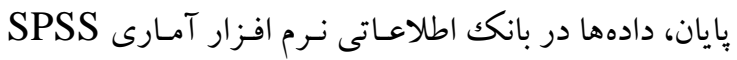

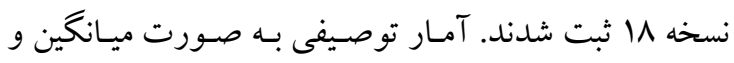

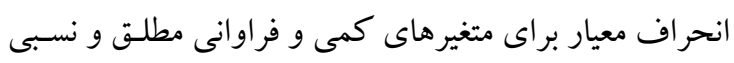
براى متغيرهاى كيفى و آمارهاى استنباطى جهت دستيابى بـهـ روابط تحليلى بر مبناى اهداف از طريق آزمونهـاى آمـارى مربع كاى و تى تست بهدست آمدند.

\section{يافته ها}

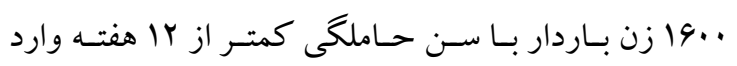
مطالعه شدند؛ ولى تحليل آمارى بر روى ...با نمونه انجـام

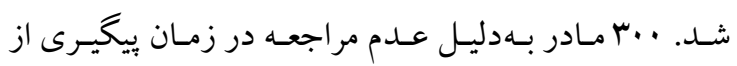
مطالعه خارج شدند. طبق جدول ا، بيشتر مـادران در هـر دو

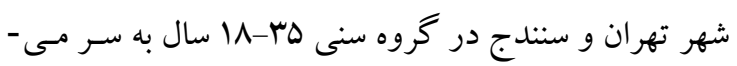

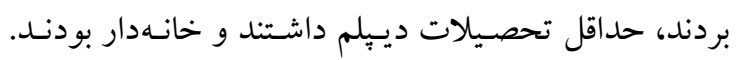
سنين زير \ا سال و بالاى ه广 سال بهدليـل خطرهـاى همـراه

جدول ا. مشخصات دموكر افيك افر اد شر كت كننده به تفكيك محل نمونه كيرى

\begin{tabular}{|c|c|c|c|c|c|c|}
\hline \multirow[t]{2}{*}{ *** P-Value } & \multicolumn{2}{|c|}{ سندج } & \multicolumn{2}{|c|}{ تهر ان } & \multirow[t]{2}{*}{ محل نمونه تيرى } & \multirow[b]{2}{*}{ ويزٔى هاى دمو كر افيكك } \\
\hline & درصد & تعداد & درصد & تعداد & & \\
\hline \multirow[t]{3}{*}{.$/ \cdot 1$} & $\% / \mathrm{V}$ & $\Delta$ & $\% \cdot 19$ & 4 & زير ها سال" & 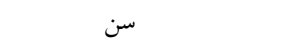 \\
\hline & $\% / .9 / 4$ & rov & $\%$ VN/ & v90 & هץ-11 سال & \\
\hline & $\% / Y / 1$ & r4 & $\%$ \%I/I & r.9 & بالاى هr سال" & \\
\hline \multirow[t]{2}{*}{.$/ \cdots 1$} & $\% / \wedge 9 / 1$ & r91 & $\% / V \Delta / r$ & $v r$. & خانهدار & | - الغل \\
\hline & $\% / 9 / r$ & TV & $\%$ \% $/ 9$ & rro & شاغل & \\
\hline \multirow[t]{2}{*}{.$/ \cdots 1$} & $\%$ & $a f$ & $1 / 9 / 4$ & 91 & زير دييلم & تحصيلات \\
\hline & $\% .9 N / Y$ & $r \cdot r$ & $\% 9 r / r$ & 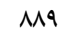 & دييلم و بالاتر & \\
\hline
\end{tabular}




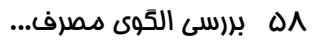

جدول ז. ويز تى هاى دمو كرافيك بر حسب مصرف خودسرانه داروها در باردارى

\begin{tabular}{|c|c|c|c|c|c|c|}
\hline \multirow[t]{2}{*}{ *P-Value } & \multicolumn{2}{|c|}{ عدم مصرف خودسر انه دارو } & \multicolumn{2}{|c|}{ مصرف خودسر انه دارو } & & \multirow[b]{2}{*}{ ويز كى هاى دمو كر افيك } \\
\hline & درصد & تعداد & درصد & تعداد & & \\
\hline \multirow[t]{2}{*}{$\cdot / r I V$} & $\% 11$ & 109 & $\%$ rV & 9 & زير دييلم & تحصيلات \\
\hline & $\% / 19$ & 1.94 & $\%$ & ro & بالاى دييلم & \\
\hline \multirow[t]{2}{*}{ - /NOr } & $\% .99 / \Delta$ & Irq. & $\%$ & $r F$ & منظم & مراقبت باردارى \\
\hline & $\% \cdot / \Delta$ & 9 & $\%$ & . & ن امنظم & \\
\hline \multirow[t]{4}{*}{.$/ \cdots 1$} & $\% . \Delta 9 / 0$ & 99. & $\%$ & $\checkmark$ & متخصص & مشاور و مر اقب دوران بارجدارى \\
\hline & $\%$ & IrT & $\%$ \%V & 9 & ماما & \\
\hline & $\% \cdot / 0$ & F & $\%$ & . & يز بزك عمومى & \\
\hline & $\%$ & f.r & $\%$ & 11 & هيج كدام & \\
\hline & & & & & & " آزمون مربع كاى \\
\hline \multicolumn{7}{|c|}{ جدول r. مشخصات بارورى افر اد شر كت كننده بر حسب مصرف خودسرانه داروها در باردارى } \\
\hline \multirow[t]{3}{*}{ *P-Value } & \multicolumn{2}{|c|}{ عدم مصرف خودسر انه دارو } & \multicolumn{2}{|c|}{ مصرف خودسرانه دارو } & مونه كيرى & محرا \\
\hline & درصد & تعداد & درصد & تعداد & & \\
\hline & & & & & & مشخصات بارورى \\
\hline \multirow[t]{2}{*}{$\cdot / \cdot 1$} & $\% 94 / 0$ & far & $\% / \%$ & 11 & $\mathrm{G}=1$ & تعداد باردارى (Gravidity) ت ت \\
\hline & $\%$ & VQF & $\%$ & 10 & $\mathrm{G}>1$ & \\
\hline \multirow[t]{2}{*}{$\cdot /$ fF } & $\% 9 \vee / \mathrm{V}$ & $1 \cdot \wedge f$ & $\% / r / r$ & rq & $A \leq 1$ & تعداد سقط (Abortion) \\
\hline & $\% 1 \cdots$ & $M$ & $\%$ & . & $A>1$ & \\
\hline \multirow[t]{2}{*}{.1 .9} & $\% 1 \ldots$ & $r$. & $\%$ & . & بلى & سابقه مردزايى \\
\hline & $\% 9 V / 0$ & 999 & $\% / Y / \Delta$ & ro & خير & \\
\hline \multirow[t]{2}{*}{.$/ \cdot 1$} & $\% 9 V / f$ & $|Y F|$ & $\% / Y / 9$ & r & خواسته & وضعيت حاملكى \\
\hline & $\%$ & F & $\%$. & 1 & ناخواسته & \\
\hline
\end{tabular}

جدول f. بيامد باردارى و زايمان به تفكيك مصرف خودسر انه داروها

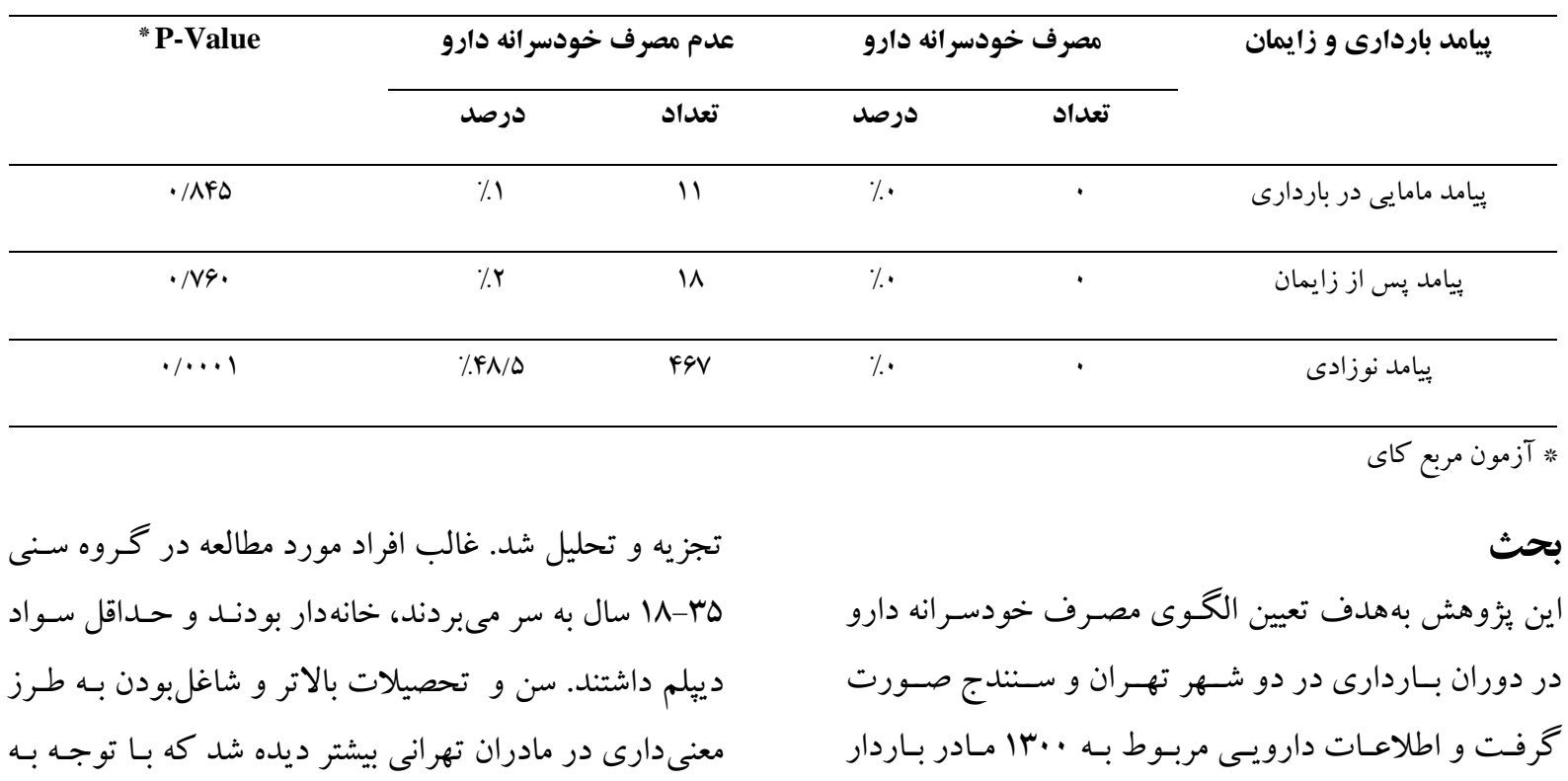


باردار جهت دريافت مراقبتهاى معمول اين دوران از سوى

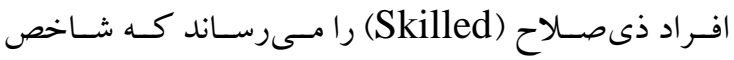

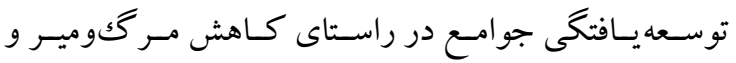

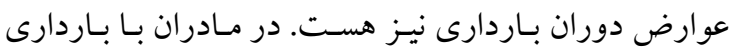

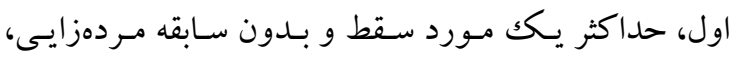
مصرف خودسرانه دارو بيشتر از سايرين بـود. هرجنــ ايـن فين رابطه از نظر آمارى معنى دار نشــ؛ ليكن در تفسير آن بايسـ

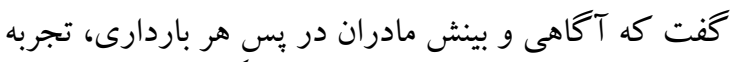

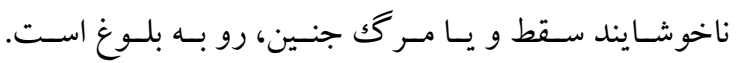

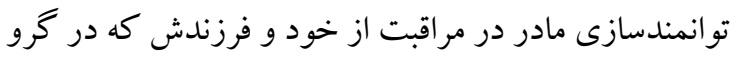

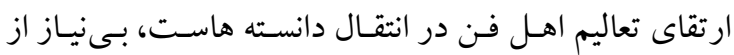
تجربه است. خود درمانى در مادران با باردارى ناخواسته بيشتر گززارش

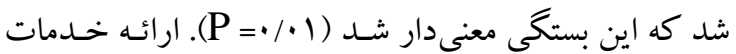

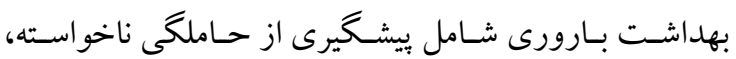

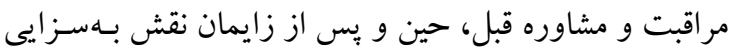

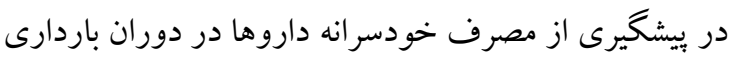
و تبعات آن خو اهد داشت. دوستدار و همكارش ( •^شا) بـه

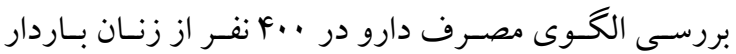

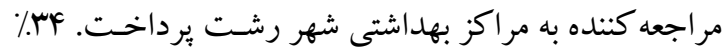
زنان قبـل بـاردارى و Fr/V\% در سـه ماهـه اول دارو مصـرف كرده بودند كه از اين ميان ه/9/1\% بهصورت خودسرانه بـود. مسـكن، آنتى بيوتيكك و داروهـاى گوارشى، داروهـاى يـر مصرف قبل باردارى را تشكيل مى دادند. بس از باردارى نيز ويتامين ها، داروهاى ضد كم خونى و گوارشى بـيش از سـاير كروههاى دارويسى مصـرف شـده بـود. بـين متغيرهـاى سـن،

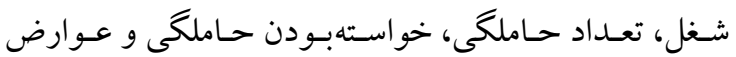
باردارى با مصرف دارو يـس از اطـلاع از بـاردارى، ارتبـاط معنسى دارى رؤيست شـــ(9). مطالعـهـ توســـ عر اقتِيـان و همكاران ( •وسا) با عنـوان بررسى الخـوى مصسرف دارو بـا توجه به طبقهبندى تعيين شده توسط FDA در زنـان بـاردار

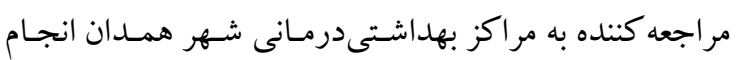

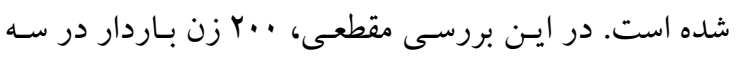

كر ايش زنان كلانشـهرى جــون تهـران بـه ادامـه تحصـيل در سطوح آموزش عالى و برخـوردارى از اسـتقلال شـغلى مسى باشد. بديهى است كه اين موضوع به ازدواج در سنين بـالا و بالطبع باردارى و زايمان دير هنگام منجر مى گردد. مـادران با مصرف خودسـرانه دارو از سـطح تحصسيلات بـايين تـرى برخـوردار بودنسـ كـهـ ايسن موضـوع حساكى از نقـش نظـام آموزشى در آكاهسازى، ايجـاد انگيـزه و در نهايست، كسـب

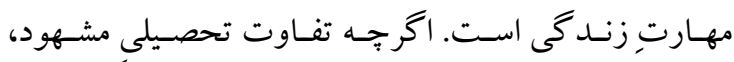
توجيه يذير بود؛ اما معنسىدار نبـود. تمـامى افر اد بـا مصـرف خودسرانه دارو، مراقبـتهــاى معمـول بـاردارى را بـه شـكل مـنظم دريافـت نمودنـــ از ايسن رو تأكيــد بــر آمسوزش در خصوص عدم مصرف خودسـر انه داروهـا بـه مـادر ان بـاردار ضمن انجام معاينات بالينى و بررسىهـاى بـاراكلينيكى، لازم و ضرورى به نظر مىرسـد. شمسى و همكـاران (IMNV)، در

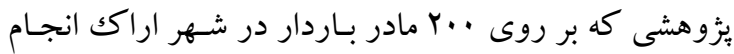

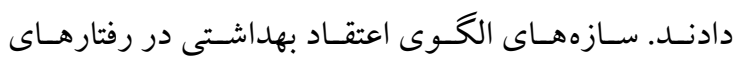
ييشخيرى كننده از مصـرف خودسـرانه دارو شـامل آكـاهى، حساسـيت، شــدت، تهلديــ، منــافع و موانـع درك شـــه، خود كار آمدى و عملكرد نهايى در قالب برسشـنامه مطرح و ارزيابى شدند. نتايج نشان داد كه آكاهى و نكخرش مادران در خصوص خـود درمـانى در دوران بـاردارى در حسد متوسط

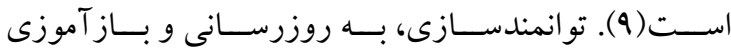
دانسته هاى بز شـكان، ماماهـا و مـر اقبين سـلامت در آمـوزش مادران باردار، آموزشهـاى رسـانهاى در اشكال گرووهى و فـردى بـه واحسدهاى مختلـف جامعسه و در نهايست طراحسى يثزوهش هـاى مقطعى و تحليلى جهـت آكـاهى از وضسعيت موجود، اخذ بازخوردِ برنامههاى آموزشسى و طراحسى جشــم اندازهاى مدتدار، همخى اثر غيرقابل انكارى بـر بيشـيرى از مصرف خودسرانه دارو خواهند داشت. بيشترين مصرف خودسرانه دارو در مادرانى گزارش شد كـه

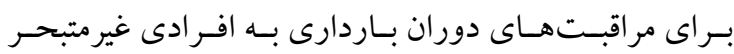
مراجعـه نمودنــ كـه از نظـر (Unskilled Assistance) آمارى نيز معنى دار شد و لزوم يوشش . ․ 


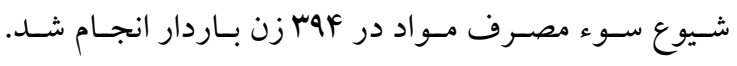
اطلاعات به شيوه مصاحبه و با استناد به اظهارات نمونههــاى

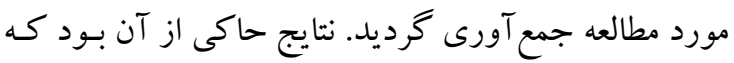

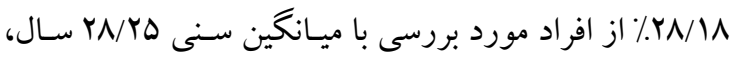

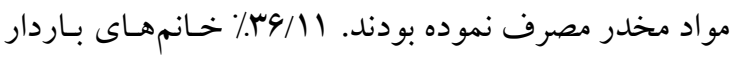

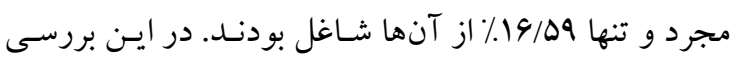

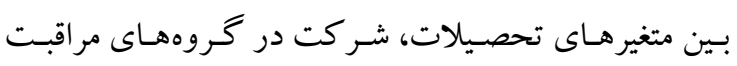

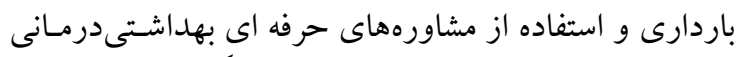
با استفاده از مواد مخـدر در دوران بـاردارى رابطه معنىدار

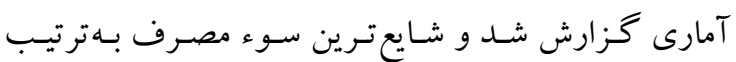

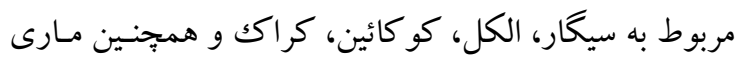

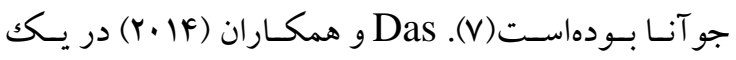
مطالعه مقطعى داروهاى تجويز شده به زنان بـاردار مر اجعهـ-

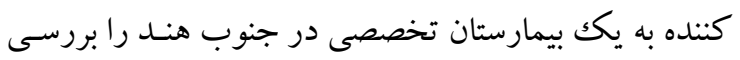
نمودند. بدين منظور 9.9 يرونده باردارى بررسى شـد.

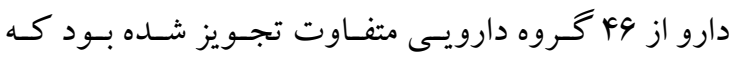
مصرف گروههاى C و B از خروههاى ديخر بيشتر بود (ه).

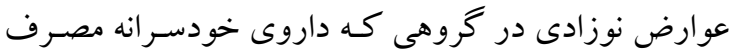

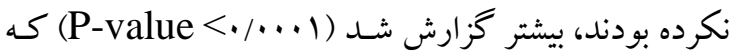

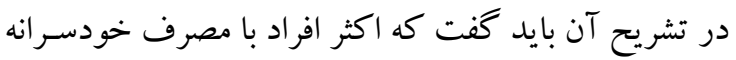
دارو بر اى مر اقبت هاى باردارى بـه افراد غيرمتبحـر مراجعـه كرده بودند كه ادامه اين روند حين زايمان و بس از آن مى -

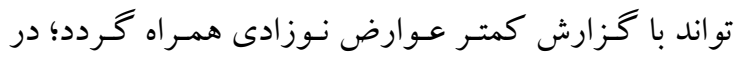

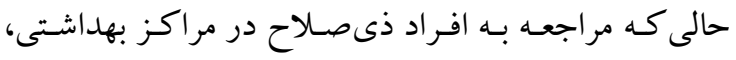

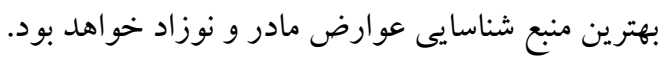

\section{نتيجه كيرى}

مصرف خودسرانه داروها در باردارى صرفاً در مـادران شهر

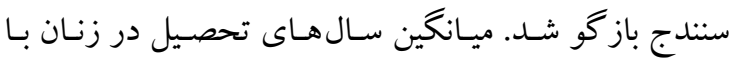

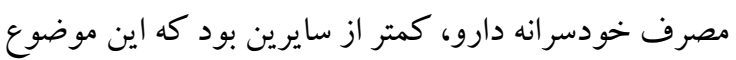

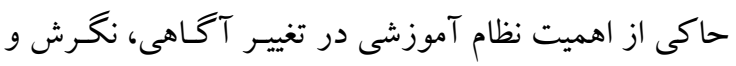

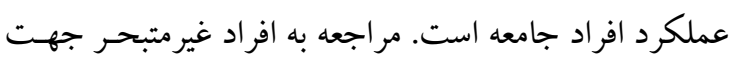

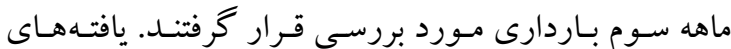

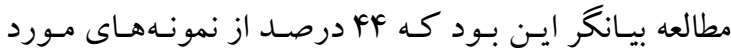
بررسى طى باردارى حداقل يكك دارو مصرف نموده بودنـد.

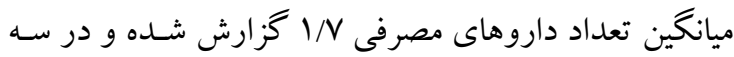

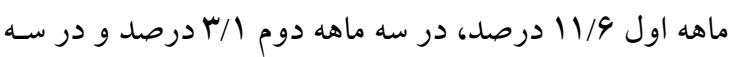
ماهه سوم ب درصد نمونههاى مورد بررسى از داروهاى طبقـه استفاده كرده بودند. بيشترين داروى مصرفى كنتراسيتيوها

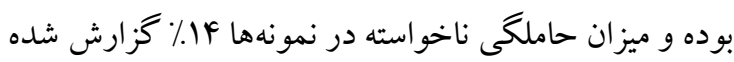

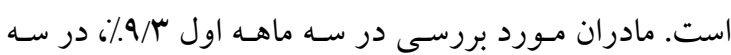

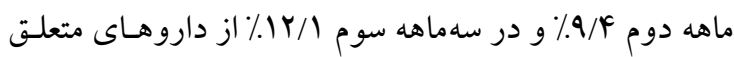
به طبقه D استفاده نموده بودند. نتايج اين يزٔوهش نشان داده دهاد

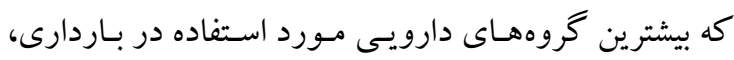
داروهاى مؤثر بر سيستم گوارش، داروهاى ضد درد و و آنتى دوردي

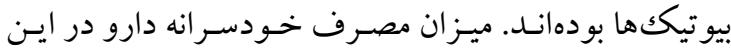

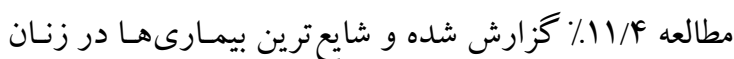
باردار كه مستلزم مصرف دارو بوده شامل اختلالات تيروئيد، ديابت و مشـكلات قلبى عروقى ذكر شـده اسـت. در ايـن يزوهش رابطه معنىدارى بين سطح تحصيلات و مصرف خودسرانه دارو گزارش شـده اسـت(f). سـهيلى و همكـاران شيو (IMM) دوران باردارى در شهر ايلام بررسى نمودند. در اين بررسى

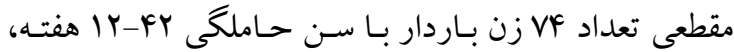
مو رد بررسى قرار گرفتند. يرسشنامهاى مشتمل بـر مشخصـات

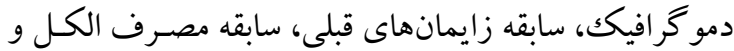

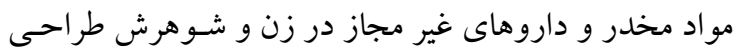
و اطلاعات به شيوه مصاحبه جمع آورى شد. يافته هاى مطالعه

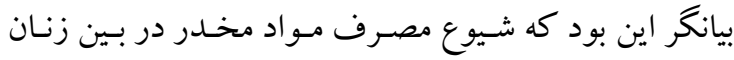

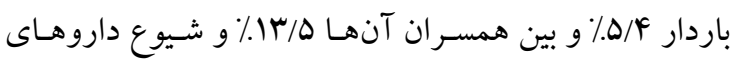

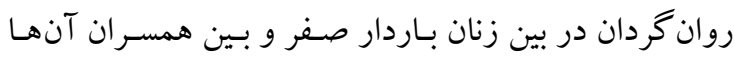

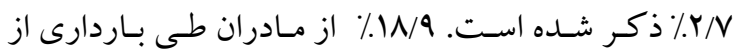

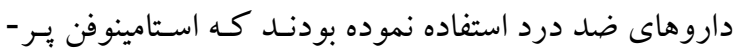

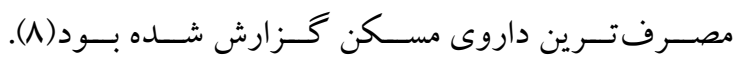
Kassada 


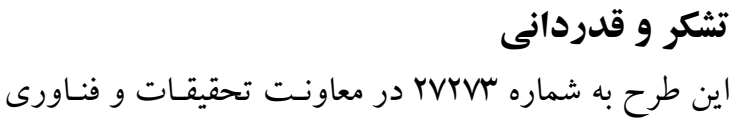

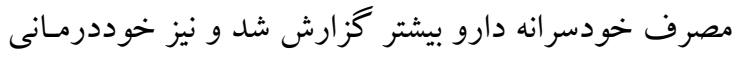

$$
\begin{aligned}
& \text { دانشگاه علوم يز شكى تهر ان به تصويب رسيد و اجرا شد. }
\end{aligned}
$$

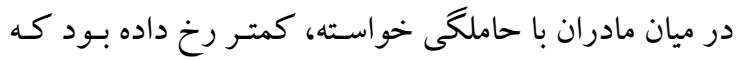

$$
\begin{aligned}
& \text { اين موضوع لزوم گسترش صددرصدى دسترسى به خدمات }
\end{aligned}
$$

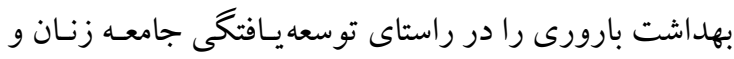

$$
\begin{aligned}
& \text { مادران ايرانى مىرساند. } \\
& \text { منابع }
\end{aligned}
$$$$
\text { دريافـت مراقبـتهـاى دوران بـاردارى در جمعيـت زنـان بـاــا }
$$

1.McCarter-Spaulding DE. Medications in pregnancy and lactation. Amer J Maternal Child Nursing. 2005; 30:10-7.

2.Adam MP, Polifka JE, Friedman JM. Evolving Knowledge of the Teratogenicity of Medications in Human Pregnancy. Am J Med Genet C Semin Med Genet 2011; 157:175182.

3.Cunningham F, Houth J, Leveno K, Rouse D, Bloom S, Spong C. Teratology and Medications That Affect the Fetus in Williams Obstetrics. 24 th ed, NewYork: Mc Graw Hill; 2014. p. 315.

4.Araghchian M, Radnia N, Salimi M, Namazi M. The Pattern of Drug Use and Their FDA Categories in Pregnant Women Referring to Medical and Health Centers in Hamadan. Sci. J. Hamadan Nurs. Midwifery Fac. 2011; 19 (1):45-55. [Persian]

5.Das S, Winston B, Sukumaran D, Kumar A, Shanthi M, Prasad J. Drug prescribing pattern in pregnancy in a secondary care hospital in south India: a retrospective study. Tropical Doctor 2016; 46 (2): 86-90.

6.Doostar Sanaye M, Sobhani AR. Pattern of drug consumption and its changes during he first trimester of pregnancy. The Journal of Qazvin Univ. of Med. Sc. 2002; 20: 55-61. [Persian]

7.Kassada DS, Marcon SS, Pagliarini MA, Rossi RM. Prevalence of drug abuse among pregnant women. Acta Paulista de Enfermagem 2013; 26 (5): 467-71.

8. Soheili F, Alizadeh S, Darash M, Yousefi A, Cheraghi M, Asadollahi KH. Prevalence of Illegal Drugs and Alcohol during Pregnancy in Ilam. Iran J Obstet Gynecol Infertil. 2012; 15(3): 22-9. [Persian]

9.Shamsi M, Karimi M, Gholamnia Z, Araban M, Kasmaie P. Measuring Health Belief Model Constructs in Preventive Behavior about Self-Medication in Pregnant Women in Arak City. Qom Univ Med Sci J. 2011; 5 (3):64-70. [Persian] 